Proceedings of SALT 26: $61-81,2016$

\title{
Assertability conditions of epistemic (and fictional) attitudes and mood variation*
}

\author{
Alda Mari \\ Institut Jean Nicod, CNRS/ENS/EHESS
}

\begin{abstract}
Italian is a well-known exception to the cross-linguistic generalization according to which belief predicates are indicative selectors across languages. We newly propose that languages that select the subjunctive with non-factive epistemic predicates allow us to see a systematic polysemy between what we call an expressive'belief' (featuring only a doxastic dimension) and an inquisitive- 'belief' (featuring both a doxastic and an epistemic dimension conveying doxastic certainty (in the assertion) and epistemic uncertainty (in the presupposition)). We offer several previously unseen contrasts proving this distinction and answer open questions about mood choice cross-linguistically. We argue that this distinction is not an idiosyncrasy of non-factive epistemics. We provide novel data, showing that fictional predicates (dream, imagine) license the subjunctive. We explain the indicative/subjunctive alternation by again disentangling expressive from inquisitive-fictional meanings. Fine-tuning the descriptions for a variety of predicates we pave the way for a new typology of attitudes relying on this systematic polysemy.
\end{abstract}

Keywords: assertability conditions, epistemic attitudes, fictional attitudes, subjunctive, indicative, presupposition.

\section{Introduction}

While the very recent debate in semantics has focused on the assertability conditions of epistemic modals (e.g. von Fintel \& Gillies 2010; Giannakidou \& Mari 2012, 2016a; Matthewson 2015; Lassiter 2016), little attention has been devoted to the assertability condition of epistemic attitudes. The present paper fills this gap starting with non-factive epistemic attitudes. To uncover these assertability conditions, we will exploit data related to mood variation in Italian, a language that licenses the

* I am particularly grateful to Anastasia Giannakidou, who has enthusiastically introduced me to the world of mood. I am also thankful to the audiences of the Workshops 'Modality and Subjectivity' and 'On (Non)veridical Expressions and Subjectivity in Language' held at University of Chicago in April 2015 and December 2015, and in particular to Chris Kennedy, Malte Willer, Itamar Francez, Paul Portner, as well as to Jacques Jayez and Pascal Amsili. All the errors and inconsistencies are mine. 
subjunctive under credere (believe) ${ }^{1}$, as in (1), thus being a notable exception to the cross-linguistic generalization according to which 'belief' predicates are indicative selectors like, for instance, French croire (believe) (2) (e.g. Farkas 1985; Quer 1998 Giannakidou 1999; Villalta 2008; Anand \& Hacquard 2013; Portner \& Rubinstein 2013).

(1) Credo che Maria sia.SUBJ / è.IND incinta.

'I believe that Mary is pregnant.'

(2) Je crois que Marie est.IND enceinte.

'I believe that Mary is pregnant.'

Our major thesis in this paper is that subjunctive under credere in Italian is not an idiosyncrasy. Languages that allow the subjunctive under 'belief' predicates allow us to see properties of non-factive epistemic verbs which are invisible in languages that select the indicative and, which, we claim, hold cross-linguistically.

Starting with non-factive epistemic predicates, we show that they are polysemous and feature what we label 'expressive' and 'inquisitive' meanings. ${ }^{2}$ Based on numerous previously unseen contrasts, and building on the distinction between matters of fact and matters of opinion, we argue that expressive-credere features only a doxastic dimension (asserting certainty) and inquisitive-credere features both a doxastic dimension (asserting certainty) and an epistemic dimension (presupposing lack of knowledge). Our proposal will be that the subjunctive is triggered whenever epistemic uncertainty is part of the assertability conditions of 'belief'. This hypothesis will provide a handle to deepen our understanding in two distinct but related areas of semantic analysis.

First, we will design a diachronic path from a stage where mood can be determined by both the presuppositional and the assertive content of the matrix predicate (represented by Italian), to a stage where mood is triggered by assertive content only (this stage is represented by French).

Second, the expressive-inquisitive distinction highlighted for non-epistemic factives is shown to cut across a variety of propositional attitudes across languages. Moving to fiction verbs in the final part of the paper, we also shed doubt on the standard assumption that they are indicative selectors (a.o. Farkas 1985; Giorgi \& Pianesi 1996; Giannakidou 1999). We argue that they also come in two variants, expressive-fictional and inquisitive-fictional, with the latter featuring epistemic uncertainty in the assertability conditions and thus licensing the subjunctive in languages where mood is sensitive to non-at issue meaning.

1 We use "'belief'" to refer to belief predicates across languages. We use italics when we refer to a specific lexical item of one specific language.

2 We consider that an expression is ambiguous when the available meanings do not share any semantic component in common, and that it is polysemous when they share a common core, see Pinkal 2003. 
Assertability conditions of epistemic (and fictional) attitudes and mood variation

The paper is structured as follows. We discuss previous attempts to explain the distributions of the Italian subjunctive in Section 2. In Section 3, we offer several contrasts for the distinction between the expressive and the inquisitive meaning of Italian credere. We also present a new analysis for this verb. We spell out our principles to explain mood variation in Section 4, which we test on a larger class of attitudes in French and Italian generalizing our proposal cross-linguistically. In Section 5 we show that the polysemy identified for non-epistemic factives is systematic and cuts across other classes of propositional attitudes. Section 6 concludes the paper offering new data for subjunctive taking sognare (dream).

\section{Previous routes and starting data}

Indistinctly across theories, mood choice is considered to be the phenomenon whereby mood in an embedded clause is determined by the semantic constitution of the matrix predicates. Such predicates have a modal semantics. Theories are divided as to whether mood choice is driven by semantic or pragmatic factors. We consider them in turn.

\subsection{Semantic approaches of mood distribution}

Semantic approaches of mood choice (e.g. Quer 1998; Giannakidou 1999; Farkas 2003; Villalta 2008; Anand \& Hacquard 2013) predict 'belief' predicates to be indicative selectors across languages by assuming a clash between (i) Hintikka (1962) semantics in (3), where $\operatorname{Dox}_{\alpha}(w)$ is a homogeneous modal base that consists of $p$ worlds, and (ii) the constraint according to which the subjunctive is triggered by the presence of alternatives in the modal base.

(3) ' $\alpha$ believe $p$ ' is true in $w$ iff $\forall w^{\prime} \in \operatorname{Dox}_{\alpha}(w), p$ is true in $w^{\prime}$

Semantic theories are mostly divided as to whether the subjunctive is triggered by alternatives that are ordered or not ordered.

Giannakidou 1999; Farkas 2003 (with the term 'undecidedness') and the revisitation in Giannakidou \& Mari 2015 propose that the subjunctive is triggered by non-ordered $p$ and $\neg p$ alternatives - namely non-homogeneity as a property of modal bases. ${ }^{3}$ By assuming Hintikka semantics for 'belief' predicates, Giannakidou \& Mari (2015) and Giannakidou (1999) before them predict 'belief' predicates to be indicative selectors, leaving the Italian subjunctive unexplained.

Giorgi \& Pianesi (1996), Villalta (2008) and Anand \& Hacquard (2013) propose instead that the subjunctive is triggered by ordered alternatives and specifically by

3 Giannakidou \& Mari (2016a, forthcoming) use the term 'non-veridicality'; Farkas (2003) uses the term 'undecidedness.' 
attitudes featuring a preferential semantics. ${ }^{4}$ Anand \& Hacquard 2013 establishes a distinction between representational attitudes using information states (believe, know, be certain) and preferential attitudes using ordered alternatives (want) as indicative and subjunctive selectors, respectively. The Italian data are again acknowledged as an exception to this generalization (see e.g. Anand \& Hacquard 2013).

To reinforce the puzzle, note that all non-factive epistemic attitudes in Italian license the subjunctive, including essere certo (be certain), as in (4a), and essere convinto (be convinced), as in (4b). ${ }^{5}$

a. Sono sicuro che l'assassino sia.SUBJ Mario.

'I am certain that the murderer is Mario.'

b. Sono convinto che l'assassino sia.SUBJ Mario.

'I am convinced that the murderer is Mario.'

Unable to explain the Italian data, Giorgi \& Pianesi (1996) resort to a different property of the Hintikka doxastic space. They argue that the Hintikka space is a 'private space' and that space privacy is a subjunctive trigger. Technically, a private space is a space that does not overlap with the common ground. This idea not only levels the question of why a belief state should be disconnected from the common ground but also leaves unexplained the case of fiction verbs (5). These, arguably, use private spaces yet license the indicative (which is in fact preferred under the interpretation in which there is no overlap between imagination/dream worlds and the common ground (5), cf. infra). The idea that 'privacy' is a subjunctive trigger is thus not tenable.

Gianni ha sognato che andava.IND a scuola.

'Gianni dreamt that he was going to school.'

\subsection{The Italian subjunctive in pragmatic theories}

In a pragmatic perspective, Schlenker (2003) and Portner \& Rubinstein (2013) propose that the subjunctive signals a lack of commitment. Portner \& Rubinstein (2013) argue that an individual is contextually committed to a modal background if he is ready to defend it as a good basis for action. They propose that 'belief' predicates convey commitment and are thus predicted to be indicative selectors, leaving the Italian subjunctive unexplained. Moreover, it must be noted that the subjunctive co-occurs unproblematically with adverbs that signal commitment as

4 This is implemented as ordering sources by Giorgi \& Pianesi (1996), and in Heimian terms by Villalta (2008); the details of these implementations are irrelevant to the present purposes.

5 For completeness, we must note that even epistemic factives can trigger the subjunctive, like essere cosciente (be aware) (unlike sapere (know). For an explanation, see Giannakidou \& Mari forthcoming. 
Assertability conditions of epistemic (and fictional) attitudes and mood variation

illustrated in (6). If the subjunctive signaled lack of commitment, the sentence would be epistemically incoherent, contrary to fact.

(6) Credo proprio che Maria sia.SUBJ incinta.

'I really believe that Mary is pregnant.'

Farkas (2003) advances instead that subjunctive signals disagreement and proposes that, in Italian, the subjunctive is an instrument to maximize the contrast between the speaker commitment (and lack thereof) in those cases where an individual other than the speaker is committed to $p$ but the speaker is not (7).

(7) Loro credono che l'assassino sia.SuBJ Mario.

'They believe that Mario is the murderer.'

This account predicts that first person belief reports should be in the indicative, contrary to fact. The subjunctive is in fact the default option in the first person.

Homer (2007) argues that the Italian credere, when combined with the subjunctive, triggers the scalar implicature 'I am not sure.' This implicature is cancelled by the indicative. As a result when the embedded verb is in the indicative, credere is a synonym of essere sicuro. This account raises two problems. First, it leaves unexplained the ability of predicates that lexically convey certainty (like essere sicuro and essere convinto) to embed a sentence with the verb in the subjunctive mood (4). Second, it is unclear how such an account posing credere and essere sicuro on the same scale could accommodate the specific lexical features of each of these items. Unlike credere, essere sicuro imposes evidential constraints and seems to require (cf. infra) indirect evidence (see (8a)). This constraint, as we will argue, is part of the assertability conditions of essere sicuro (see von Fintel \& Gillies (2010) for a similar constraint on English epistemic modal must).

(8) Looking at a car:

a. \#Sono sicuro che è.IND bella.

'I am certain that she is nice.'

b. Credo che è.IND / sia.SUBJ bella.

'I believe that she is nice.'

\section{Expressive and Inquisitive 'belief': New data and analysis}

\subsection{New data}

We propose that credere (and indeed 'belief' predicates in French, and likely in English) has two meanings: 'expressive' and 'inquisitive'. Expressive-credere 
features only a doxastic dimension and appeals to a solipsistic mental state ${ }^{6}$. Only one layer of meaning is present (this is the Hintikkean belief). Expressive-credere can be used when there is no fact of the matter at stake.

Inquisitive-credere, instead, features a doxastic and an epistemic dimension. Two layers of meaning can be distinguished. In the assertion, inquisitive-credere conveys doxastic certainty. It conveys epistemic uncertainty in the presupposition. Doxastic certainty manipulates opinions. Epistemic (un)certainity manipulates matters of facts (for an overview of the distinction between doxastic and epistemic modal base see Portner 2009 and references therein). Inquisitive-credere can only be used when a matter of fact is at stake, i.e. when $p$ is objectively settled (it has a truth value). Inquisitive-credere triggers the subjunctive.

Expressive and inquisitive-credere share the assertive meaning, namely doxastic certainty. We now provide evidence for the distinction between these two meanings. Predicates of personal taste. Beyond dissimilarities across the vast literature on predicates of personal taste (PPT), at least in the relativist tradition (a.o. Lasersohn 2005; Stephenson 2007), authors agree that PPT do not have wordly truth-makers In other words, there is not fact of the matter at stake. As a consequence, one cannot 'know' whether $p$ is true or false objectively. With this idea in mind, let us consider (9). The tastiness of the soup is not a 'fact of the matter' and no ratification is possible of the tastiness of the soup (on ratification, see Mari 2015b).

(9) The soup is tasty.

Let us now consider PPT embedded under 'belief' predicates, as in (11). This English sentence can be translated in two different ways in Italian, by using either the indicative (11a) or the subjunctive (11b) in the embedded clause.

(10) I really believe that you are stupid.

(11) a. Credo davvero che sei.IND un cretino.

b. Credo davvero che tu sia.SUBJ un cretino.

These two sentences have a different impact on the hearer. By choosing (11a), the speaker intends to make his/her own belief known. S/he is expressing her/his personal conviction, regardless of the facts. The credere in the matrix clause has an 'expressive' meaning, it is the Hintikka credere. It features only a doxastic dimension and no epistemic dimension is involved here.

Refining (9), the best translation for the example (11b) is in (12).

(12) All things considered, I really believe that you are stupid.

6 See also the notion of 'origo space' in Garrett 2001 
Assertability conditions of epistemic (and fictional) attitudes and mood variation

With (11b), the speaker intends to convey that s/he is looking for facts proving the stupidity of the addressee and (11b) is felt as more insulting than (11a) because it conveys that there is a fact of the matter out there and that the participants to the conversation can find out whether $p$ (the addressee being stupid) is objectively true. The speaker conveys that $\mathrm{s} /$ he does not know how the matter is settled, but $\mathrm{s} / \mathrm{he}$ is also conveying that there is a fact to know and that a ratification of $p$ is in principle possible (hence the polemic and indeed amusing tone of the sentence).

Restating the observation otherwise, the subjunctive allows us to see layer of epistemic uncertainty in the predicate credere. Credere in (11b) is inquisitive, and, unlike expressive-credere, it conveys not only doxastic certainty but also epistemic uncertainty. The speaker does not know how $p$ is settled (epistemic uncertainty), but believes that $p$ is true (doxastic certainty).

Futurity? It is possible to use the subjunctive in embedded clauses to describe events that have not happened yet. Consider the scenario in (13). The party has not happened yet at the time of utterance and the event of John coming to the party is in the future w.r.t the time of the belief.

(13) Scenario: We are organizing a party and John is invited. Usually John does not come to parties, however, he is very much in love with Mary and Mary is coming for sure.

Credo che venga.SUBJ anche Gianni questa volta.

'I believe that John is coming too this time.'

Indicative can also be used to describe events that have not happened at the time at which the attitude is held (in the future tense under an attitude verb in the present).

Consider now a different scenario.

(14) Scenario: My son has a tendency to forget stuff at school. My husband wants to buy an expensive scarf and asks me whether it is a good idea. I reply:

Credo che la perderà.IND.FUT.

'I believe that he will lose it.'

In the scenario in (14), the subjunctive is impossible.

(15) Scenario: see (14).

\#Credo che la perda.SUBJ.

'I believe that he will lose it.'

Why is this the case? Because the future has not happened yet $p$ does not have a truth value at the time of utterance. With future events, the subjunctive with epistemic non-factives ${ }^{7}$ can only be used when there is a plan. Consider (16a).

7 We come back in the conclusion to bouletic attitudes. 
The Olympics happening in Tokyo is a planned event. The subjunctive is possible. France losing against Portugal tomorrow is not a planned (nor plannable) event and the subjunctive is out (16b) (the indicative is compatible with both planned and unplanned events). ${ }^{8}$

a. Credo che le Olimpiadi del 2020 si svolgano.SUBJ a Tokyo.

I believe that the Olympics of 2020 will take place in Tokyo.

b. \#Credo che la Francia perda.SUBJ, questa sera.

I believe that France will lose tonight.

We will follow Copley 2002 in assuming that, given the existence of a plan, the truth value of $p$ is already fixed at the time of utterance. ${ }^{9}$

Capitalizing on these distributions, we can conclude that expressive-credere embedding an indicative clause can be used when no facts of the matter are at stake. Inquisitive-credere, embedding a subjunctive clause can be used when there is a fact of the matter at stake ${ }^{10}$ (or the speaker acts as if there were one, see (11b)) and, besides doxastic certainty, it conveys epistemic uncertainty about the truthiness of $p$. 'In fact I know' continuation. Expressive and inquisitive-credere differ as to their (in)compatibility with 'in fact I know' continuation. Expressive-credere seems compatible with it.

(17) Credo che Dio esiste.IND, anzi, so che esiste !

'I believe that God exists, in fact I know that he exists!'

Note that this use of 'know' is not standard, as $p$ is not presupposed. No matter what the status of knowledge is here, the sequence is unproblematic.

With inquisitive-credere, the 'in fact I know' continuation requires belief revision. Based upon adding or recalling extra information, the continuation induces retraction of the belief sentence, which is to be considered false.

(18) Scenario: Two policemen are trying to determine the manufacturer of a car involved in an accident.

Credo che sia.SUBJ una Fiat, anzi, (ora che ci penso bene) so che è una Fiat. ' $I$ believe it is a Fiat, in fact, now that I think it through, I know that it is a Fiat'.

8 The subjunctive is in the present tense, there is no future subjunctive in Italian.

9 See also (Condoravdi 2001; Mari 2015c) on metaphysical settledness with plans. We do not endorse here, however, any specific assumptions about metaphysical unsettledness.

10 Note that (15) is perfect in a different scenario where my son has a habit of losing his scarf, and the embedded sentence describes such a habit. In such configuration the habit already holds at the time of utterance. Note also that with statives the subjunctive cannot refer to a future state of affairs: 'Credo che sia malato' (I believe that he is sick). 
Assertability conditions of epistemic (and fictional) attitudes and mood variation

That the belief sentence needs to be retracted, shows that it features an epistemic uncertainty assertability condition, which it is absent from the expressive meaning of credere. This case of retraction (signaled by 'now that I think it through') is to be distinguished from metalinguistic negation, which requires focus (see Amsili \& Guida 2014 for French). ${ }^{11}$

(19) Non solo "credo" che sia.SUBJ una Fiat, lo "so" !

'I do not only "believe" that it is a Fiat, I "know" it!'

Epistemic uncertainty as an assertability condition. As the data in (18) already shows, epistemic uncertainty appears to be part of the definedness conditions of inquisitive-credere. This meaning component, moreover, does not disappear under negation. $^{12}$

(20) Non credo che sia una Fiat, ma non lo so con sicurezza.

'I do not believe that it is a Fiat, but I do not know for sure.'

We also note that credere cannot be used if the attitude holder knows $p$.

(21) Scenario: Seeing the rain.

\#Credo che piova.SUBJ

I believe that it rains.

This piece of evidence has been extensively discussed in relation with epistemic must (which is equally out in this context) and has lead theoreticians either to argue that epistemic must presupposes indirect evidence (von Fintel \& Gillies 2010) or that it presupposes lack of knowledge (Giannakidou \& Mari 2016a).

For credere, (21) shows that it presupposes lack of knowledge. Indeed credere can be used when the attitude holder has direct evidence, as in (8b). As we have already argued, there is no fact of the matter with PPT (there is no fact of the matter for 'being nice'), hence, $p$ cannot be 'known'. In other terms, PPT allow us to disentangle lack of knowledge from (in)direct evidence. In the context provided in

11 The reader should be warned, when evaluating these sentences, not to build examples where credere takes two individual arguments, either by using a pronoun 'lo' or a clitic 'ci'. These disrupt the pattern observed here, and enhance a 'believe-in' interpretation.

12 For extended discussion see Sauerland 2008. Note that all of the following are perfect in Italian.

(i) a. Mario fumava, ma ha smesso di fumare. 'Mario used to smoke, but he stopped.'

b. Mario ha smesso di fumare, ma fumava.

'Mario stopped smoking, but he used to smoke.' 
(21) credere is felicitous, thus showing that it presupposes lack of knowledge rather than lack of direct evidence.

To conclude, we can safely distinguish between two meanings for the verb credere. The expressive meaning, conveying 'credence' and the inquisitive meaning conveying 'conjecture'. We render this distinction by proposing that the first one features a doxastic layer only, whereas the second features a doxastic and an epistemic layer.

\subsection{Analysis: The meanings of credere and 'belief' verbs}

Tools Let $i$ be the attitude holder, ${ }^{13}$ and let $E_{i}\left(w_{0}\right)$ and $\mathscr{D}_{i}\left(w_{0}\right)$ be sets of propositions. $E_{i}\left(w_{0}\right)$ and $\mathscr{D}_{i}\left(w_{0}\right)$ represent what the attitude holder $i$ knows in $w_{0}$ and what the attitude holder $i$ believes in $w_{0}$, respectively. $\cap E_{i}\left(w_{0}\right)$ is an epistemic modal base the set of worlds compatible with what the attitude holder $i$ knows in $w_{0} ; \cap \mathscr{D}_{i}\left(w_{0}\right)$ is a doxastic modal base, $i$ 's belief worlds (generalizations, past experience, biases, stereotypes, ...). $\mathscr{D}_{i}\left(w_{0}\right)$ can be used as a doxastic ordering source. Best $\mathscr{D}_{i}\left(w_{0}\right)$ delivers the set of worlds in the epistemic modal base that comply with $i$ 's beliefs (see Portner 2009 on Best).

$$
\operatorname{Best}_{\mathscr{D}_{i}\left(w_{0}\right)}:\left\{w^{\prime} \in \cap\left(E_{i}\left(w_{0}\right)\right): \forall q \in\left(\mathscr{D}_{i}\left(w_{0}\right)\right)\left(w^{\prime} \in q\right)\right\}
$$

Finally, we will say that $p$ is objectively settled if and only if it has a truth value. Given this framework, our analysis for expressive and inquisitive-credere (credere $\mathscr{E}$ and credere $\mathscr{I}$, respectively, in the formulas) are as follows.

Expressive-credere. Expressive-credere is the Hintikka belief. It features a solipsistic mental state. Expressive-credere is compatible with $p$ being objectively settled. (It does not require settledness of $p$, as (11a) and (14) show).

Expressive-credere. $\left[\left[i \text { credere }_{\mathscr{E}} p\right]\right]^{i, \mathscr{D}}=1$ iff $\forall w^{\prime}\left(w^{\prime} \in \cap \mathscr{D}_{i}\left(w_{0}\right) \rightarrow p\left(w^{\prime}\right)\right)$

All the worlds in the doxastic modal base are $p$ worlds.

Negation can be interpreted upstairs (24a) (and the resulting interpretation is roughly 'doubt') or in situ (24b) (the resulting interpretation is 'believe that $\neg p$ '). ${ }^{14}$
a. $[[i \text { not credere } \mathscr{E} p]]^{i, \mathscr{D}}=1$ iff $\neg \forall w^{\prime}\left(w^{\prime} \in \cap \mathscr{D}_{i}\left(w_{0}\right) \rightarrow p\left(w^{\prime}\right)\right)$
b. $\left[\left[i_{\text {not credere }} p\right]\right]^{i, \mathscr{D}}=1$ iff $\forall w^{\prime}\left(w^{\prime} \in \cap \mathscr{D}_{i}\left(w_{0}\right) \rightarrow \neg p\left(w^{\prime}\right)\right)$

13 A.o. Farkas 1985, Giannakidou 1999, Lasersohn 2005.

14 To disentangle the two interpretations, we would have to assume, for (24a), that there is at least one $p$ world in the doxastic space. We will work under this assumption from now on, for all lexical entries involving negation. 
Assertability conditions of epistemic (and fictional) attitudes and mood variation

Inquistive-credere. Our analysis for inquisitive-credere is in (25). Two layers of meaning are involved: an epistemic layer (in the presupposition) and a doxastic layer (in the assertion). Lack of knowledge is presupposed and belief is asserted. Inquisitive-credere presupposes that $p$ is objectively settled.

Inquisitive-credere.

a. $\left[\left[i \text { credere }_{\mathscr{I}} p\right]\right]^{E, i, \mathscr{D}}$ is defined iff it $p$ is objectively settled at the time at which the attitude is held and $\left(\exists w^{\prime \prime} \in \cap E_{i}\left(w_{0}\right)\left(\neg p\left(w^{\prime \prime}\right)\right)\right) \wedge\left(\exists w^{\prime \prime \prime} \in\right.$ $\left.\cap E_{i}\left(w_{0}\right)\left(p\left(w^{\prime \prime \prime}\right)\right)\right)$ (The epistemic modal base contains $p$ and $\neg p$ worlds.)

b. If defined $\left[i\right.$ credere $\left.\left._{\mathscr{I}} p\right]\right]^{E, i, \mathscr{D}}=1$ iff $\forall w^{\prime}\left[w^{\prime} \in \operatorname{Best}_{\mathscr{D}_{i}\left(w_{0}\right)}\left(p\left(w^{\prime}\right)\right)\right]$

All worlds of the epistemic modal base that comply with $i$ 's beliefs are $p$ worlds.

With the negation interpreted upstairs, inquisitive-credere means dubitare ('doubt').

a. $[[i \text { not credere } \mathscr{I} p]]^{E, i, \mathscr{D}}$ is defined iff (25a). If defined,

b. $[[i \text { not credere } \mathscr{I} p]]^{E, i, \mathscr{D}}=1$ iff $\neg \forall w^{\prime}\left[w^{\prime} \in \operatorname{Best}_{\mathscr{D}_{i}\left(w_{0}\right)}\left(p\left(w^{\prime}\right)\right)\right]$

The negation can also be interpreted in situ (and the resulting interpretation is $i$ believes that $\neg p$ ).

a. $[[i \text { not credere } \mathscr{I} p]]^{E, i, \mathscr{D}}$ is defined iff (25a). If defined,

b. $[[i \text { not credere } \mathscr{I} p]]^{E, i, \mathscr{D}}=1$ iff $\forall w^{\prime}\left[w^{\prime} \in \operatorname{Best}_{\mathscr{D}_{i}\left(w_{0}\right)}\left(\neg p\left(w^{\prime}\right)\right)\right]$

We hypothesize that the expressive and the inquisitive variants hold crosslinguistically and establish a comparison between Italian and French.

\section{New principles of mood variation and first set of predictions}

\subsection{Principles of mood choice}

Our proposal relies on the notion of homogeneity. ${ }^{15}$ Modifying Giannakidou \& Mari 2016b we propose (28) (for any modal space M, we assume that $\mathbf{M}$ is not empty). ${ }^{16}$

15 The term is already used in Giannakidou \& Mari 2012, 2016a, forthcoming; Smirnova 2013; it is known as 'decidedness' in Farkas 2003, and 'diversity' in Condoravdi 2001.

16 We use positive-homogeneity, non-homogeneity and negative-homogeneity instead of veridicality, non-veridicality and antiveridicality. In Giannakidou \& Mari 2016b both veridical and antiveridical spaces are homogeneous. 
Positive-homogeneity, non-homogeneity and negative-homogeneity

a. A modal space $\mathrm{M}$ is positively-homogeneous with respect to a proposition $p$ iff $\forall w^{\prime}\left(w^{\prime} \in \mathbf{M} \rightarrow p\left(w^{\prime}\right)\right)$

b. A modal space $\mathrm{M}$ is non-homogeneous with respect to a proposition $p$ iff $\exists w^{\prime}, w^{\prime \prime} \in \mathbf{M}\left(w^{\prime} \neq w^{\prime \prime} \wedge\left(p\left(w^{\prime}\right) \wedge \neg p\left(w^{\prime \prime}\right)\right)\right.$

c. A modal space $\mathrm{M}$ is negatively-homogeneous with respect to a proposition $p$ iff $\mathrm{M} \cap p=\emptyset$.

$\mathscr{D}_{i}\left(w_{0}\right), \mathscr{E}_{i}\left(w_{0}\right)$ and $\mathrm{Best}_{\mathscr{D}_{i}\left(w_{0}\right)}$ are modal spaces.

We assume the following definedness conditions for indicative and subjunctive.

(30) a. Indicative is licensed iff the modal space $M$ is homogeneous, i.e. it contains either only $p$ worlds or only $\neg p$ worlds.

b. Subjunctive is licensed iff the modal space $\mathrm{M}$ contains at least some $\neg p$ worlds ( $\mathrm{M}$ is either non-homogeneous or negatively homogeneous).

Indicative is selected if either $p$ or $\neg p$ is added to the worldview of the speaker and the modal space $\mathrm{M}$ is homogeneous. This differentiates us from e.g. Giannakidou (1999) who claims that indicative is selected when the propositional attitude is veridical, i.e. $p$ is entailed. As for the subjunctive, note that, unlike Giannakidou \& Mari (forthcoming), we do not claim that it is triggered by non-homogeneity. Rather, it is semantic negation that triggers the subjunctive (Giannakidou 199917; Quer 2009). Also, note that, when the modal base is negatively-homogeneous, both the indicative and the subjunctive are well-defined. In this case, the conditions determining the choice in context are pragmatic, as we shall show.

Following Mari 2014, 2015a, we propose that, in some languages, mood is sensitive to both the content in the presupposition and in the assertion (see also Giannakidou \& Mari 2015, forthcoming for further developments of this idea) and distinguish two types of languages, as follows.

(31) a. Type- $\pi$ languages: mood choice is driven by both presuppositional and assertive content.

b. Type- $\alpha$ languages: mood choice is driven by assertive content only.

\subsection{Mood choice with 'belief'}

Italian is a type- $\pi$ language. Coming back to expressive-credere in (23), in the positive form, our analysis predicts that only indicative is allowed, because of

17 Giannakidou (1999) states that subjunctive is triggered by non-veridicality, i.e. $p$ is not entailed. Antiveridicality ( $\neg p$ is entailed) is a sub-case of non-veridicality. 
Assertability conditions of epistemic (and fictional) attitudes and mood variation

positive-homogeneity in the set $\operatorname{Best}_{\mathscr{D}_{i}\left(w_{0}\right)}$. As for inquisitive-credere in (25), this predicts that both subjunctive (because of non-homogeneity in the epistemic modal base (25a), as given in the presupposition) and indicative (because of homogeneity in Best $_{\mathscr{D}_{i}\left(w_{0}\right)}(25 \mathrm{~b})$, as given in the assertion) are licensed.

To explain the overwhelming use of the subjunctive with inquisitive-credere, we rely on the Gricean maxim of quantity. In our case, this would require to use, in the embedded clause, the mood that better resolves the polysemy of the embedding matrix verb, thus maximizing the information about its meaning. The indicative does not allow one to distinguish between expressive and inquisitivecredere. Since the indicative is the only option with expressive-credere and both subjunctive and indicative are available options with the inquisitive-credere, the indicative is dispreferred with the latter. The indicative thus becomes the preferred mood for expressive-credere and the subjunctive is thus preferred for inquisitivecredere. ${ }^{18}$

For expressive-credere under negation, we predict that the subjunctive is the only option under the 'doubt' interpretation in (24a); when negation is interpreted in situ (24b), both indicative (because of homogeneity in the belief space) and subjunctive (because of negative-homogeneity in the belief space) are predicted to be allowed, as confirmed by the facts (32).

(32) Non credo che Babbo Natale esiste.IND/esista.SUBJ.

'I do not believe that Santa Claus exists.'

As for inquisitive-credere in negative sentences, we predict that the subjunctive is the only option under the 'doubt' interpretation in (26) (because of non-homogeneity both in the epistemic space (in the presupposition) and in the belief space (in the the assertion)). When the negation is interpreted in situ as in (27) both indicative (because of homogeneity in the belief space in the assertion) and subjunctive (because of non-homogeneity in the epistemic space in the presupposition and negative homogeneity in the belief space in the assertion) are allowed. This prediction is borne out, as both subjunctive and indicative are again possible, see (33).

Gianni non crede che Mario sia.SUBJ arrivato/è.IND arrivato.

'John does not believe that Mario has arrived.'

We submit that the indicative is preferred when $p$ is presupposed to be true by the participants in the conversation, ${ }^{19}$ but it is unknown by the attitude holder (34): ${ }^{20}$

18 Indicative is allowed with inquisitive-credere because of homogeneity in the belief space. However, while attested, this use of the indicative is strongly dispreferred, in comparison to the indicative with expressive-credere and the subjunctive with inquisitive-credere.

19 We thank an anonymous reviewer for promoting this solution.

20 Upon subscribing to Homer's hypothesis that presupposition creates an intervention effect, this explains why strong NPI cannot be used when the indicative is chosen (Homer 2007). 
(34) Non crede che si trova.IND a due metri dalla cima.

'He does not believe that he is at two meters from the top of the mountain.'

As we have suggested, the lexical entries in (23) and (25) can be generalized cross-linguistically and we explicitly propose that croire (believe) in French share the semantics of Italian credere. We use 'believe', to signal that the lexical entries are valid for 'belief' predicates cross-linguistically.

Expressive-'believe'. $[[i \text { 'believe' } \mathscr{E} p]]^{i, \mathscr{D}}=1$ iff $\forall w^{\prime}\left(w^{\prime} \in \cap \mathscr{D}_{i}\left(w_{0}\right) \rightarrow p\left(w^{\prime}\right)\right)$

(36) Inquisitive-'believe'.

a. $[[i \text { 'believe' } \mathscr{I} p]]^{E, i, \mathscr{D}}$ is defined iff $p$ is objectively settled at the time at which the attitude is held and $\left(\exists w^{\prime \prime} \in \cap E_{i}\left(w_{0}\right)\left(\neg p\left(w^{\prime \prime}\right)\right)\right) \wedge$ $\left(\exists w^{\prime \prime \prime} \in \cap E_{i}\left(w_{0}\right)\left(p\left(w^{\prime \prime \prime}\right)\right)\right)$

b. If defined $[[i \text { 'believe' } \mathscr{I} p]]^{E, i, \mathscr{D}}=1$ iff $\forall w^{\prime}\left[w^{\prime} \in \operatorname{Best}_{\mathscr{D}_{i}\left(w_{0}\right)}\left(p\left(w^{\prime}\right)\right)\right]$

We propose that French is a type- $\alpha$ language. This explains that indicative is chosen with both expressive and inquisitive-croire. With the latter, given homogeneity in the belief space in the assertion (in $\operatorname{Best}_{\mathscr{D}_{i}\left(w_{0}\right)}(36 \mathrm{~b})$ ), the indicative is the only available option (see (2)).

For expressive-'belief', two different interpretations arise with negation interpreted upstairs and in situ. For French, the predictions are parallel to those for Italian (for space reasons, we do not repeat the entries here). For inquisitive 'belief' across languages, we obtain (37a) when negation is interpreted upstairs and (38) with negation interpreted in situ.

a. [[i not 'believe' $\mathscr{I} p]]^{E, i, \mathscr{D}}$ is defined iff (36a). If defined

b. $[[i \text { not 'believe' } \mathscr{I} p]]^{E, i, \mathscr{D}}=1$ iff $\neg \forall w^{\prime}\left[w^{\prime} \in \operatorname{Best}_{\mathscr{D}_{i}\left(w_{0}\right)}\left(p\left(w^{\prime}\right)\right)\right]$

a. [[inot 'believe' $\mathscr{I} p]]^{E, i, \mathscr{D}}$ is defined iff (36a). If defined

b. $[i$ not 'believe' $\mathscr{I} p]]^{E, i, \mathscr{D}}=1$ iff $\forall w^{\prime}\left[w^{\prime} \in \operatorname{Best}_{\mathscr{D}_{i}\left(w_{0}\right)}\left(\neg p\left(w^{\prime}\right)\right)\right]$

In French, the subjunctive is mandatory under the 'doubt' interpretation (37). Both indicative and subjunctive are possible with inquisitive-croire in negative sentences (38) (Best $_{\mathscr{D}_{i}\left(w_{0}\right)}$ is both homogeneous (hence indicative) and negativelyhomogeneous (hence subjunctive)). The pragmatic restrictions observed for Italian seem to hold in French as well (Amsili \& Guida 2014). ${ }^{21}$

21 The same expressive-inquisitive polysemy seems to hold for essere sicuro and essere convinto, allowing both indicative and subjunctive.

Sono sicuro/convinto che è.IND/siasUBJ l'assassino. 
Assertability conditions of epistemic (and fictional) attitudes and mood variation

\subsection{Cross-linguistic corroboration of the hypothesis}

Our hypotheses about the principles of mood choice presented in Section 4.1, are corroborated by considering a larger set of propositional attitudes. In French (39) and Italian (40) we observe the following pattern.

(39) French

a. Non factive epistemics (e.g. croire (believe)): Indicative

b. Emotive-factives (e.g. être irrité (be irritated)): Subjunctive

Italian

a. Non factive epistemics (e.g. credere (believe)): Subjunctive

b. Emotive-factives (e.g. essere irritato (be irritated)) Subjunctive (or Ind.)

Under any theory for emotive factives we are aware of (e.g. Farkas 2003; Baunaz 2015; Giannakidou \& Mari forthcoming), (i) factivity (or at least subjective veridicality ( $p$ being entailed in the belief space)) in the presupposition triggers indicative, and (ii) emotivity in the assertion triggers subjunctive (theories diverge as for why emotivity triggers the subjunctive; we do not consider these differences here). Important for us is that French selects the subjunctive with emotives, but the indicative with epistemic non-factives. This can be explained under our view that French is a type- $\alpha$ language, with mood choice being driven by the content in the assertion. $^{22}$

I am certain/convinced that he is the murderer.

Essere sicuro and essere convinto add evidential constraints to the semantics of 'belief' predicates (inducing important consequences with respect to the veridicality of $p$ in the subjective or the objective space). Corroborating the data in (8a), showing that essere sicuro is incompatible with direct evidence, we note that essere sicuro can be typically used in deductive contexts, again showing that essere sicuro features an indirect evidence constraint. This predicate thus also supports the entailment of $p$ in both the epistemic and the objective space. Be convinced, instead, while expressing certainty, seem to presuppose an inner source of evidence (endogenous vs. exogenous evidence for essere sicuro). The design of the interplay between these assertability conditions and the systematic polysemy will be the topic of a different study.

(ii) The ball is either in A, B or C. - It is neither in A nor in B.

Sono sicuro che è in C./\#Credo/\#Sono convinto che sia.SUBJ/è.IND in C.

I am certain that it is in $\mathrm{C} / \# \mathrm{I}$ believe/\#I am convinced that it is in $\mathrm{C}$.

22 Note that this cannot be explained under an optimality based framework à la Farkas 2003 or Giannakidou \& Mari forthcoming where either homogeneity or non-homogeneity ((un)decideness or (non)veridicality, in the authors terms) wins. 
Furthermore, diachronic findings show that the subjunctive with emotive-factives is a recent innovation of French (Patard \& de Mulder 2016). It is also interesting to note that, in Italian, the indicative is not entirely banned. This would show that in Italian there is still sensitivity to the content in the presupposition for emotivefactives as well. Together, these observations lead us to submit that mood choice across languages is undertaking a path from a stage at which it is determined by both presuppositional and assertive content to a stage where it is determined by assertive content only. Balkan languages, in which both epistemic non-factives and emotive factives select the indicative would be at a further stage of development, at which assertivity, in a semantic sense (adding $p$ or $\neg p$ in the worldview of the speaker) determine mood choice (Giannakidou 1999; Farkas 2003).

\section{More predictions: Systematic polysemy of fiction verbs}

The polysemy of 'belief'-predicates is not an idiosyncrasy. When generalized to fictional predicates, the distinction between expressive and inquisitive-attitudes allow us to discover data that has not previously been noticed or considered.

It is commonly argued that 'dream, and 'imagine' are indicative selectors crosslinguistically. This is due to the fact that they are assertive (on the account of Farkas 2003) or subjectively veridical (on the accounts of Giannakidou 1999; Giannakidou $\&$ Mari 2015) i.e. they add $p$ to the worldview of the speaker. Anand \& Hacquard 2013 explain that they are representational and are thus indicative selectors (see also Giorgi \& Pianesi 1996). The semantics standardly proposed for fictional attitudes is a modification of the Hintikka semantics for epistemic predicates, where dream/imaginary spaces replace the doxastic one. We use 'imagine' for the class of fictional predicates cross-linguistically. The function Im (for Imagination) thus replaces Dox in (3), ceteris paribus.

' $\alpha$ 'imagine' $p$ ' is true in $w$ iff $\forall w^{\prime} \in \operatorname{Im}_{\alpha}(w), p$ is true in $w^{\prime}$

Prima facie this hypothesis is borne out by the data in Italian as well, (42).

(42) Sognava/Immaginava che andava.IND in Italia.

'He dreamt/imagined that he was going to Italy.'

However, it has not previously been noticed that fiction verbs can license the subjunctive, as shown by the Italian data.

(43) Scenario: Giacomo, who is 35 years old, used to sing very well when he was a child. A friend of mine, who has known Gianni since he was born, utters: Immagino che Gianni sia.SUBJ una pop star oramai.

'I imagine that Gianni is a pop star by now.' 
Assertability conditions of epistemic (and fictional) attitudes and mood variation

Here 'imagine' has a conjectural meaning. $p$ is objectively settled ${ }^{23}$ and the speaker does not know how the matter $(p)$ is settled. Let us indeed consider a different scenario (48) in which Gianni is not a popstar, and this is not a possibility given the facts. In such scenario, 'imagine' cannot convey conjecture and the subjunctive is out.

(44) Scenario: Gianni is now 10 years old and he is known not to be a pop star.

a. Immagino che Gianni è.IND una pop star.

b. \#Immagino che Gianni sia.SUBJ una pop star.

'I imagine that Gianni is a pop star.'

As for 'belief' predicates, we submit that 'imagine' predicates are also polysemous and feature an expressive and an inquisitive interpretation. We propose that there is a correlation between meaning and mood choice and that the subjunctive is triggered by epistemic uncertainty in the presupposition with the inquisitive meaning.

We propose the two following lexical entries for expressive (45) and inquisitive'imagine' (46). The ordering source is now $\mathscr{F}_{i}\left(w_{0}\right)$ (where $\mathscr{F}$ stands for 'Fiction').

Expressive-'imagine'. [[i 'imagine' $\mathscr{E} p]^{i, \mathscr{D}}=1$ iff $\forall_{s} w^{\prime}\left(w^{\prime} \in \cap \mathscr{F}_{i}\left(w_{0}\right) \rightarrow p\left(w^{\prime}\right)\right)$

(46) Inquisitive- 'imagine'

a. $\left[[i \text { 'imagine' } \mathscr{I} p]^{E, i, \mathscr{F}}\right.$ is defined iff ip is objectively settled at the time at which the attitude is held and $\left(\exists w^{\prime \prime} \in \cap E_{i}\left(w_{0}\right)\left(\neg p\left(w^{\prime \prime}\right)\right)\right) \wedge\left(\exists w^{\prime \prime \prime} \in\right.$ $\left.\cap E_{i}\left(w_{0}\right)\left(p\left(w^{\prime \prime \prime}\right)\right)\right)$

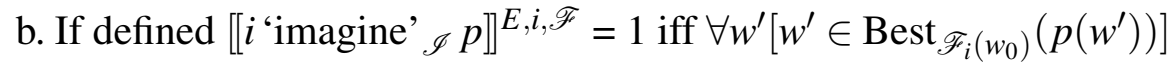

Under the expressive- 'imagine' only imaginary worlds are considered and no facts are taken into account. Under the inquisitive- 'imagine' epistemic and imaginary worlds are considered, with $\mathscr{F}_{i}\left(w_{0}\right)$ as the ordering source. The principles in Section 4.1 govern mood choice with fictional predicates.

\section{Conclusion and perspectives}

In this paper we have studied mood distribution with non-factive epistemics and fictional attitudes. Our analysis of mood has treated subjunctive as a negative polarity item licensed by semantic negation (Giannakidou 1999; Quer 2009). We have

23 As with inquisitive credere, $p$ must have a truth value at $t_{u}$ as the futurity test shows.

(i) \#Immagino che la Francia perda domani.

I imagine that France will lose tomorrow 
innovated in three respects, presenting numerous new pieces of evidence. First, in opposition to monosemous accounts of 'belief' predicates, we have proposed a polysemy based view, one of the meanings of 'belief' predicates featuring epistemic uncertainty in the presupposition. Second, we have used both presuppositional and assertive content to explain mood variation cross-linguistically without resorting to an optimality framework (pace Farkas 2003; Giannakidou \& Mari 2015, forthcoming). We have instead designed a new diachronic path undertaken by the languages studied here. Third, we have shown that the systematic polysemy observed for nonfactive epistemics holds for other classes of propositional attitudes, and specifically fiction verbs. Future research will show how far this systematic polysemy goes. As far as we see today, it seems to extend to numerous classes, including experiential verbs like 'find' (Mari 2015a ${ }^{24}$ ), and verbs of mental acts like 'understand' and 'conceive.'

Moving towards a more fine-grained typology, we newly note that, pace Giorgi \& Pianesi (2001), sognare (dream), in Italian, also licenses the subjunctive.

Sogno che la Francia perda.SUBJ domani.

I dream that France looses tomorrow.

As with imaginare, epistemic uncertainty is the subjunctive trigger. Consider (48). The subjunctive version sounds amusing, as it presupposes that it is an epistemic possibility for the attitude holder that the Martians arrive. The indicative version is the report of a dream, with no connection to the reality.

Sogno che arrivino.SUBJ i Marziani/arrivano.IND i Marziani. I dream that the Martians arrive.

The parallelism with immaginare also has limitations, though. First, inquisitive 'dream' uses a bouletic ordering source. Moreover, inquisitive- 'dream' does not presuppose that $p$ already has a truth value (47), as it is compatible with nonplannable events. We submit that, in this respect, sognare patterns like sperare (hope), which also features an epistemic uncertainty layer (see also Portner \& Rubinstein 2013), without presupposing objective settledness of $p$. The presentation of the data and the discussion of the details are left out for a future study. As for now, it seems reasonable to assume that the subjunctive taking credere is to be understood within a larger cartography of attitudes that takes into account their systematic polysemy.

24 Trovare che (find that) licenses the subjunctive in Italian. Mari 2015a codes collective epistemic uncertainty as an assertability condition of trovare che and claims that this is the subjunctive trigger. 
Assertability conditions of epistemic (and fictional) attitudes and mood variation

\section{References}

Amsili, Pascal \& Floriane Guida. 2014. Vers une analyse factorielle de l'alternance indicatif/subjonctif. In SHS Web of Conferences, 2313-2331.

Anand, Prnav \& Valentine Hacquard. 2013. Epistemics and attitudes. Semantics and Pragmatics 6. 1-59.

Baunaz, Lena. 2015. On the various sizes of complementizers. Probus 27. 193-236.

Condoravdi, Cleo. 2001. Temporal interpretation of modals - modals for the present and for the past. In Brady Clark David Beaver, Stefan Kaufmann \& Luis Casillas (eds.), The Construction of Meaning, 59-88. CSLI Publications.

Copley, Bridget. 2002. The semantics of the future. Cambridge MA: MIT PhD dissertation.

Farkas, Donka. 1985. Intensional Descriptions and the Romance Subjunctive. New York: Garland.

Farkas, Donka. 2003. Assertion, belief and mood choice. Talk presented at ESSLLI, Vienna.

von Fintel, Kai \& Anthony Gillies. 2010. Must...stay... strong ! Natural Language Semantics 18(4). 351-383.

Garrett, Edward John. 2001. Evidentiality and assertion in Tibetan. Los Angeles: University of California $\mathrm{PhD}$ dissertation.

Giannakidou, Anastasia. 1999. Affective dependencies. Linguistics and Philosophy 22(4). 367-421.

Giannakidou, Anastasia \& Alda Mari. 2012. The future of Greek and Italian: an epistemic analysis. In Vincent Homer Emmanuel Chemla \& Grégoire Winterstein (eds.), Sinn und Bedeutung 17, 255-270. Semantics Archive.

Giannakidou, Anastasia \& Alda Mari. 2015. Mixed (non)veridicality and mood choice in complement clauses: starting with emotive verbs. Ms. University of Chicago and Institut Jean Nicod.

Giannakidou, Anastasia \& Alda Mari. 2016a. Future and universal epistemic modals: reasoning with non-veridicality and partial knowledge. In Blaszack Joanna et al. (ed.), Tense, Mood, and Modality: New Answers to Old Questions, Chicago: Chicago University Press.

Giannakidou, Anastasia \& Alda Mari. 2016b. The semantic roots of positive polarity: epistemic modal verbs and adverbs in Greek and Italian. Ms. University of Chicago and IJN.

Giannakidou, Anastasia \& Alda Mari. forthcoming. Emotive predicates and the subjunctive: a flexible mood ot account based on (non)veridicality. Proceedings of Sinn und Bedeutung 20.

Giorgi, Alessandra \& Fabio Pianesi. 1996. Tense and Aspect. Oxford: Oxford University Press. 
Giorgi, Alessandra \& Fabio Pianesi. 2001. Imperfect dreams: the temporal dependencies of fictional predicates. Probus 13(1). 31-68.

Hintikka, J. 1962. Knowledge and Belief. Cornell: Cornell University Press.

Homer, Vincent. 2007. Intervention effects: The case of presuppositions.: UCLA MA thesis.

Lasersohn, Peter. 2005. Context dependence, disagreement, and predicates of personal taste. Linguistics and Philosophy 28(6). 643-686.

Lassiter, Dan. 2016. Must, knowledge and (in)directedness. Natural Language Semantics 24(2). 117-163.

Mari, Alda. 2014. Actuality entailments: broadening the space of the possibilities. Linguistic Colloquium, University of Chicago, December 2015. Available at http://ling.auf.net/lingbuzz/002634.

Mari, Alda. 2015a. Epistemic attitudes consensus and truth. Workshop on Modality and Subjectivity. University of Chicago, April 2015. doi:http://jeannicod.ccsd.cnrs.fr/ijn_01353392.

Mari, Alda. 2015b. French future: Exploring the future ratification hypothesis. Journal of French Language Studies FirstView. 1-26. doi:10.1017/S0959269515000289.

Mari, Alda. 2015c. Modalités et Temps: Des modèles aux données. Bern: Peter Lang.

Matthewson, Lisa. 2015. Evidential restrictions on epistemic modals. In Luis Alonso-Ovalle \& Paula Menendez-Benito (eds.), Epistemic Indefinites, Oxford: Oxford University Press.

Patard, Adeline \& Walter de Mulder. 2016. Le développement du subjonctif après les verbes de sentiment. Talk at Tam-e Conference, Paris.

Pinkal, Manfredi. 2003. Towards a semantics of precization. In Thomas T. Ballmer \& Manfred Pinkal (eds.), Approaching Vagueness, 13-57. Amsterdam: NorthHolland.

Portner, Paul. 2009. Modality. Oxford: Oxford University Press.

Portner, Paul \& Aynat Rubinstein. 2013. Mood and contextual commitment. In Anca Cherches (ed.), Semantics and Linguistic Theory (SALT) 22, 636-659. Ithaca, NY: CLC.

Quer, J. 2009. Twists of mood: The distribution and interpretation of indicative and subjunctive. Lingua 119(12). 1779-1787.

Quer, Joseph. 1998. Moods at the interfaces. Utrecht: OTS PhD dissertation.

Sauerland, Uli. 2008. Implicated presuppositions. In Anita Steube (ed.), Sentence and Context: Language, Context and Cognition, 269-310. Berlin and New York: Mouton de Gruyter.

Schlenker, Philippe. 2003. The lazy Frenchman's approach to the subjunctive: Speculations on reference to worlds and semantic defaults in the analysis of 
Assertability conditions of epistemic (and fictional) attitudes and mood variation

mood. In Ivo van Ginneken Twan Geerts \& Heike Jacobs (eds.), Romance Languages and Linguistic Theory 2003, 269-310. Amsterdam: John Benjamins. Smirnova, A. 2013. Evidentiality in Bulgarian: Temporality, epistemic modality, and information source. Journal of Semantics 30. 479-532.

Stephenson, Tamina. 2007. Judge dependence, epistemic modals, and predicates of personal taste. Linguistics and Philosophy 30(4). 487-525.

Villalta, Elisabeth. 2008. Mood and gradability: an investigation of the subjunctive mood in Spanish. Linguistics and Philosophy 31(4). 467-522.

\author{
Alda Mari \\ Institut Jean Nicod \\ ENS \\ Pavillon Jardin \\ 29, rue d'Ulm \\ 75005 Paris - France \\ alda.mari@ens.fr
}

